\section{筧 Springer}

Available online at https://link.springer.com/journal/42241

http://www.jhydrodynamics.com

Journal of Hydrodynamics, 2020, 32(2): 414

https://doi.org/10.1007/s42241-020-0015-3

Journal of Hydrodynamics, 2020, 32(2): 414

Published 2020 April, doi: 10.1007/s42241-020-0015-3

\title{
Erratum to: Experimental investigations of transient pressure variations in a high head model Francis turbine during start-up and shutdown
}

\author{
Chirag Trivedi, Michel J. Cervantes, B. K. Gandhi, Ole Gunnar Dahlhaug
}

\section{ERRATUM TO: Journal of Hydrodynamics doi: 10.1007/s42241-018-0114-6}

In the published article [1] there is an error in the listing of the last author. "Dahlhaug G. Ole" should be "Ole Gunnar Dahlhaug" as listed in this erratum.

In the published Erratum [2], the following sentence appearing at the second paragraph has been published incorrectly.

In the published article "Vaginal adhesions in a woman with the history of dystocia". Journal of Hydrodynamics, 2014, 26(2): 277-290. doi: 10.1016/S1001-6058(14)60031-7," the spell of author's name is given incorrectly.

The correct sentence should be:

In the published article "Experimental investigations of transient pressure variations in a high head model Francis turbine during start-up and shutdown. Journal of Hydrodynamics, 2014, 26(2): 277-290.

doi: 10.1016/S1001-6058(14)60031-7," the spell of author's name is given incorrectly.

The Editorial Office apologizes for any inconvenience that it may have caused.

\section{References}

[1] Trivedi C., Cervantes M. J., Gandhi B. K. et al. Experimental investigations of transient pressure variations in a high head model Francis turbine during start-up and shutdown [J]. Journal of Hydrodynamics, 2014, 26(2): 277-290. https://doi.org/10.1016/S1001-6058(14)60031-7

[2] Trivedi C., Cervantes M. J., Gandhi B. K. et al. Erratum to: Experimental investigations of transient pressure variations in a high head model Francis turbine during start-up and shutdown [J]. Journal of Hydrodynamics, 2018, 30(5): 974.

https://doi.org/10.1007/s42241-018-0114-6 